\title{
Rio de Janeiro Literary Guide: Strolling Through Short Stories and Newspaper Chronicles In The First Decades of the $20^{\text {th }}$ Century
}

XXIV International Conference

of the Iberoamerican Society

of Digital Graphics

Medellin | Colombia

\author{
Rodrigo Cury Paraizo \\ LAURD/PROURB/FAU/UFRJ | Brasil | rparaizo@fau.ufrj.br \\ Cíntia Mechler de Carvalho \\ LAURD/PROURB/FAU/UFRJ | Brasil | cintia.carvalho@fau.ufrj.br \\ Marcela Aurélia da Silva \\ LAURD/PROURB/FAU/UFRJ | Brasil | marcela.aurelia@fau.ufrj.br \\ Raissa da Rocha Paim \\ LAURD/PROURB/FAU/UFRJ | Brasil | raissa.paim@fau.ufrj.br
}

\begin{abstract}
This paper discusses locative media as the basis of a virtual heritage project about the awareness of literary works involving distinct places in downtown Rio de Janeiro. The goal is to build a responsive website in form of a literary guide depicting the urban scenery of the city in the first decades of the 20th century, helping visitors and city dwellers alike to perceive the city that was in contrast to the city in the present.
\end{abstract}

Keywords: Locative media; Augmented spaces; Virtual heritage; Rio de Janeiro; Literary tourism.

\section{INTRODUÇÃO}

Esse artigo aborda experiências com mídias locativas no âmbito do turismo literário e da memória social e urbana do Rio de Janeiro. Mais especificamente, trata-se do processo de desenvolvimento de um site responsivo, elaborado pelo Laboratório de Análise Urbana e Representação Digital do Programa de Pós-graduação em Urbanismo da Faculdade de Arquitetura e Urbanismo da Universidade Federal do Rio de Janeiro (LAURD/PROURB/FAU/UFRJ), com o objetivo de permitir que o usuário-leitor possa visualizar e experienciar uma camada de narrativas sobre um período da cidade, obtendo uma nova visão da cidade e compreendendo a memória local.

Trata-se de um guia literário sobre a cidade, construído como um mapa interativo no qual estão marcados trechos geo-localizados de contos e crônicas que se passam na cidade, escritos nos anos 1920, com a finalidade de permitir ao usuário-leitor perceber os diversos pontos da cidade em que a narrativa literária se imbrica com a narrativa e com o espaço urbanos, e que ajudam a descrever a cidade e suas dinâmicas nesse período, trazendo à tona registros e impressões de um período de grandes transformações urbanas. O recorte histórico representa um momento de grande modernização da cidade, tanto do ponto de vista urbanístico, que tem entre seus marcos a Exposição do Centenário de 1922, realizada na região do Castelo, quanto do ponto de vista dos costumes e da sociedade.
A partir desse banco de dados de obras literárias, buscouse uma perspectiva da cidade de um ponto de vista mais ligado à dinâmica da vida urbana do que à descrição urbanística da cidade. Tomamos por base a representação das ambiências urbanas por meio das ações e personagens retratados em obras como contos e crônicas de Lima Barreto, Benjamim Costallat, Manuel Antônio de Almeida, Théo-Filho, Orestes Barbosa e Felippe D'Oliveira, entre outros.

Neste artigo, são discutidos os fundamentos pelos quais a mídia locativa pode contribuir para a produção de lugares, a partir da posição do usuário no espaço urbano e da apresentação de informações que enriquecem as narrativas a respeito desse espaço. O lugar é formado, então, a partir dessas narrativas, mediando nossa experiência social e atuando na relação usuário, mídia e espaço.

\section{O RIO DE JANEIRO NOS ANOS 1920}

O Rio de Janeiro se caracterizou, ao longo de sua história, por grandes transformações urbanas, que alteraram consideravelmente tanto a sua paisagem original quanto as continuidades históricas. Assim, os sucessivos aterros, culminando no Aterro do Flamengo, mudaram a relação dos bairros centrais da cidade com o mar; e as demolições dos morros do Castelo e do Santo Antônio eliminaram lugares de origem da própria cidade; renovações urbanas de abertura das avenidas Central (atual Rio Branco) e Presidente Vargas eliminaram tanto tecidos residenciais consolidados quanto diversos lugares de afirmação cultural, como a Praça Onze. Essa contínua alteração da 
base física da cidade, tanto geomorfológica quanto edilícia, tornam mais difícil estabelecer as relações com os diferentes períodos históricos que compõem uma cidade.

As duas primeiras décadas do século $\mathrm{XX}$ foram marcadas por profundas mudanças na cidade do Rio de Janeiro, em diferentes setores, escalas e dimensões, como descrito por Santucci (2015), Sant'Ana (2008), Castro (2019), Kessel (2001), Abreu (1987), entre outros.

Trata-se de um período de grandes transformações urbanas, que se iniciam com a construção da Avenida Central, inaugurada em 1906, e têm seu marco final na elaboração do Plano Agache, publicado já no início da década de 1930, passando pelos desmontes dos morros do Castelo e de Santo Antônio. Em meio a demolições e remoções, aterros e construções, as ruas da cidade foram se preparando para a circulação de automóveis, bondes elétricos e de novas redes técnicas. Em 1920, como aponta Castro (2018, pos. 416), por exemplo, as ruas mais importantes da cidade já tinham iluminação elétrica consta que havia mais lâmpadas no Rio do que em Paris. A imagem da cidade se desenhava tanto para cumprir seu papel de capital republicana do país quanto de um destino efetivamente moderno (e próspero) para o olhar estrangeiro - e seu capital.

A Exposição do Centenário de 1922, em comemoração à independência do Brasil, de certo modo, simboliza todas essas características: ao mesmo tempo que sinalizou avanços na própria ideia de cidade para a sociedade carioca, marcou o período final de desmonte do Morro do Castelo. De acordo com Motta, a comemoração do centenário da independência do Brasil, em 1922, "suscitou debates sobre a formação e as perspectivas da sociedade brasileira" (1994, p. 2).

As medidas de embelezamento urbano da capital foram marcadas também pela progressiva expulsão dos mais pobres do Centro em direção aos subúrbios da Zona Norte, seja pelo aumento dos aluguéis, seja pela demolição de edifícios por razões de salubridade ou para dar lugar às novas ruas e avenidas da capital. A expansão para a Zona Sul, por sua vez, também foi iniciada nesse período, por uma elite em busca de refúgio da agitação da área central, consolidando a ocupação de Copacabana - e seu icônico calçadão -, Ipanema e Leblon, e reinventando o hábito de frequentar as praias (é nesse momento que as casas litorâneas cariocas começam a ter suas frentes voltadas para o mar).

Por outro lado, havia grande afluência de europeus de diversos extratos sociais, "imigrantes desenraizados que circulavam anônimos em busca de oportunidades em meio a uma população recém-saída da escravidão" (SANTUCCI, 2015, p. 30), potencializando as diversas trocas culturais.

Com inúmeras editoras, pelo menos quinze jornais diários, e mais de $65 \%$ da população alfabetizada (CASTRO, 2018, pos. 582-596), o Rio em 1920 era uma cidade com muitas oportunidades para os escritores, principalmente na forma de crônicas e livros que buscavam narrar as diferentes e sempre vibrantes pulsações da cidade, da alta política nacional à crítica de costumes, passando pelas transformações urbanas. Com isso, escritores como Lima
Barreto, Benjamim Costallat, Théo-Filho e Felippe D'Oliveira, entre outros, se dispunham a narrar e comentar o vibrante cotidiano carioca, registrando as transformações da cidade e da vida urbana.

Nos dias atuais, a Avenida Central, atual Rio Branco, já teve seu perfil substancialmente modificado, em que pese a recente implementação do VLT remeter aos bondes que em 1920 ali circulavam; a região do Castelo pouco lembra a Exposição e menos ainda a fundação da cidade; a Rua do Ouvidor, ainda que mantenha a agitação comercial, nem sempre consegue evidenciar sua herança e sua história (Figura 1).

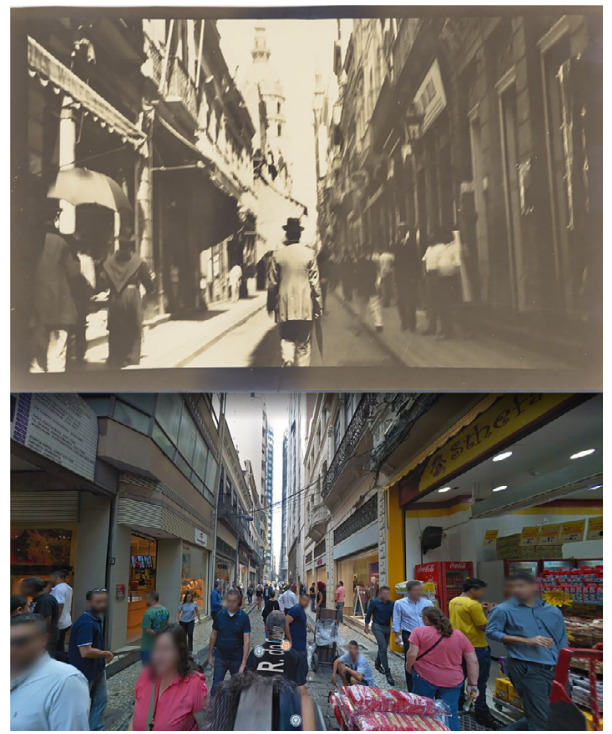

Figura 1: Rua do Ouvidor, no Centro do Rio de Janeiro, c. 1920 e cem anos depois. Fontes: Instituto Moreira Salles e Google Street View.

Por outro lado, a memória coletiva da cidade faz pouca referência ao período, deixando de reconhecer uma cidade altamente vanguardista e progressista. O trabalho, portanto, quer contribuir para a recuperação dessa memória, valorizando o papel do Rio de Janeiro como cidade capaz de abrigar as diferenças e as inovações.

\section{NARRATIVAS E LUGARES}

O turismo literário pode ser entendido como uma modalidade do turismo cultural que se baseia na visita aos lugares físicos que inspiraram determinadas obras literárias ou que influenciaram de algum modo a vida dos autores dos textos (MENDES, 2007, p. 73; COUTINHO, FARIA E FARIA, 2016; SARDO, 2008). Nas palavras de Salvador e Baptista (2011, p. 2), ele proporciona aos leitores "o poder de experimentar os lugares reais ou imaginários das obras ou das vidas dos seus autores".

A prática pode ser entendida a partir de uma questão inerente ao próprio olhar do turista; MacCannell (1999. P. 41) define uma atração turística como uma relação empírica entre o turista, a vista da atração (sight) e o marcador (marker). Este último é entendido como uma 
peça de informação sobre aquilo que é visto pelo olhar do turista, seja por meio de guias turísticos, cartazes, mapas ou apenas do nome do objeto em uma etiqueta. Os marcadores são indícios para o turista que asseguram autenticidade e significado à experiência de visitação, ajustando o lugar do objeto visitado na representação social da mente do turista.

No caso do turismo literário, a "peça de informação" é uma obra de arte literária com uma narrativa relativamente fechada, ou seja, que busca ter uma existência e um valor artístico independentes dos lugares que eventualmente descreva. Traz como características o envolvimento emocional característico da literatura que, no caso, permite relacionar as narrativas imaginadas durante a leitura do texto aos espaços físicos reais experienciados pelo leitorturista quando em visita. Com isso, o que se busca é uma perspectiva efetivamente social e humana para os espaços, para além de um olhar estritamente descritivo, o que certamente amplia seu alcance junto aos leitoresturistas, trazendo mais envolvimento destes com os espaços.

A atividade de interpretação patrimonial, por outro lado, tem por base justamente relacionar o objeto patrimonial com diferentes narrativas, que tenham ressonância especialmente emocional - com o público. Com isso, fica enriquecido também o processo de constituição dos lugares na cidade (ANDRADE E BASTOS, 2017, p. 205), alimentados por essas narrativas e olhares e permitindo singularizar uma diversidade maior de espaços urbanos. Conhecer os diferentes relatos compostos pelos escritores cariocas do início do século XX é ampliar a camada narrativa da cidade, descobrindo não apenas diferentes olhares para a cidade, mas uma sociedade diferente da atual; e também espaços totalmente distintos, contribuindo para construir uma percepção mais profunda da importância da cidade e seu povo - e do potencial de ambos. Na construção de ambientes interpretativos digitais, ou patrimônio virtual, a mediação digital procura facilitar o acesso a essa camada de narrativas (REFSLAND et al, 2000; ADDISON, 2006).

É o processo de transformação de espaços em lugares, quando os primeiros adquirem definição e sentido (TUAN, 2007,p.136), tornando-se espaços inscritos, qualificados e valorizados (GODIN E MUHLETHALER, 2005, p. 36). Duarte define o lugar como "uma porção do espaço onde um grupo de pessoas ou um indivíduo sedimentam seus valores culturais de modo a depositar nele suas referências" (2002, p.46). Ao facilitar o acesso a essas histórias, é possível fomentar a construção desse sentido de identificação dos espaços em lugares, contribuindo para a apropriação desses espaços - e suas memórias coletivas - pela população.

\section{HISTÓRIA E MEMÓRIA EM MÍDIAS LOCATIVAS}

Lemos (2009, p. 2) define mídias locativas como "dispositivos, sensores e redes digitais sem fio e seus respectivos bancos de dados 'atentos' a lugares e contextos", de modo que "reagem informacionalmente aos mesmos", por meio de trocas info-comunicacionais dinâmicas entre lugar e dispositivo.
A expressão, portanto, é usada para fazer referência ao uso de mídias que possuem informações geolocalizadas e tem a finalidade de permitir determinadas interações com o local baseadas na experiência e ações do usuário. De acordo com Zeffiro (2012, p.251), o termo "locative media" foi cunhado por Karlis Kalnins durante o Art+Communication Festival em 2003, na Letônia, para designar a produção artística a partir de tecnologias baseadas em localização, com o objetivo de explorar como afetam as noções de espaço e organização social nesse espaço (BILANDZIC E FOTH, 2012, p. 66). Ainda segundo Zeffiro, pode ser entendida como um campo de produção cultural, sujeito a diversos embates, choques e apropriações, mais do que uma tecnologia.

Embora seja possível apontar cartazes e sinalizações impressas em geral na cidade como versões analógicas de mídias locativas, a versão digital traz duas características importantes: por um lado, estabelece uma relação da informação com o lugar que é, em essência, potencialmente dinâmica; ainda que possa não acontecer dessa forma, essa possibilidade estará sempre latente. A outra característica é que a informação depende de um dispositivo para ser percebida pelo usuário: sem o recurso ao dispositivo, ela permanece pairando invisível sobre o lugar. Esse fenômeno de associação de informações dinâmicas com se sobrepondo ao espaço físico é denominado por Manovich (2007, p. 251) como "espaço aumentado".

Ela pode se basear na sinalização eletrônica do dispositivo - posição dada por GPS ou acesso a sinais de Bluetooth, redes wifi ou RFID - ou ser disparada pela interação com objetos físicos - como quando o usuário aponta a câmera do celular para um QR Code, em que a percepção do usuário do objeto físico é essencial para iniciar o processo. Lemos (2009) agrupa as mídias locativas em cinco categorias: anotações urbanas eletrônicas, mapeamento, redes sociais móveis, jogos computacionais e mobilizações inteligentes.

As mídias locativas têm tido grande relevância no que diz respeito ao estudo de diferentes temas como vigilância, sociabilidade e percepção de espaço (SOUZA E SILVA, 2013), uma vez que eles aumentam a fisicalidade de um lugar para tornar visíveis suas propriedades sociais invisíveis. À medida que mudam nossos limites físicos e noções de espaço percebidos, eles também afetam nossas interações e práticas sociais dentro desses limites (BILANDIZIC E FOTH, 2012). Com o uso das mídias locativas, é possível reinventar esses limites, uma vez que, como afirma Lemos (2009), novas mídias produzem novas espacialidades.

O aplicativo Sekai Camera (Tonchidot Corporation, 2009) foi pioneiro ao usar a realidade aumentada combinada com mídias sociais para ter a cidade como camada para interação. A ideia seria permitir ao usuário marcar comentários, avaliações e fotografias que pudessem ser visualizados no celular ao apontar para o local em questão. Apesar de laureado na categoria "Entretenimento e estilo de vida" no World Summit Award em 2010, premiação para inovações digitais, a difusão ainda incipiente da realidade aumentada à época acabou levando à pouca difusão do aplicativo e sua descontinuidade em 2013 (MEDEIROS, 2014, p. 55-56). 
Um dos exemplos de jogos em mídias locativas é o aplicativo Actionbound (ACTIONBOUND, 2012), na verdade uma plataforma de criação e distribuição de caças ao tesouro e guias de visitação interativos, na qual é possível criar desafios espaciais personalizados. Eles permitem ao usuário explorar um território através de um jogo com perguntas e respostas ou percursos descritivos e ilustrados, complementando a experiência do local com estímulos à observação, comparação e aprendizado (Figura 2). Durante a pesquisa para elaboração do guia literário, conduzimos alguns experimentos com a plataforma, avaliando a possibilidade de criar mini roteiros lineares de visitação interativa a partir de um autor ou tema específicos.

O lançamento mais recente, e talvez mais inusitado, é do aplicativo Randonautica (Randonauts, LLC, 2019): segundo os desenvolvedores, a ideia é ter uma experiência "verdadeiramente aleatória" e levar o usuário a descobrir locais desconhecidos. Suas coordenadas são geradas por meio de pontos quânticos aleatórios. Com apenas alguns meses de uso, o aplicativo tem gerado diversos relatos inusitados sobre as explorações locais.

Um dos exemplos mais antigos de expressão digital dos locais relacionados à literatura teve início ainda na década de 1990. Criada em 1998, a associação "Terres d'écrivains" tem por objetivo promover os lugares da França marcados pela literatura e pela escritura, promovendo roteiros, encontros, e associações literárias. O website da associação traz diversas postagens contendo a história dos lugares, além de fotos e endereços. Em sua postagem auto descritiva (http://www.terresdecrivains.com/L-association-Terres-decrivains), a associação reconhece a riqueza de lugares habitados ou visitados pelos escritores e a importância que tiveram no desenvolvimento de suas obras, assim como o próprio poder evocativo que tais lugares possuem até os dias atuais.

$\mathrm{Na}$ etapa de construção do repertório técnico para desenvolvimento do aplicativo, foram estudados ainda alguns exemplos de guias online de cidades, com especial atenção para casos que envolvessem objetos culturais em geral, e documentos históricos e literários em particular. O aplicativo Nativoo! (SBTUR, 2013), por exemplo, permite que o usuário encontre, baseado em suas preferências, rotas de viagens criadas por outros usuários próximo a sua localidade ou que crie uma rota para compartilhar, maximizando o tempo de exploração da cidade com os roteiros pré programados. Já o aplicativo ArchiMap! (2017) reúne centenas de edifícios importantes, entre os mais conhecidos e também edifícios protegidos de cidades como Barcelona, Londres e Chicago, permitindo que o usuário encontre e se guie por rota até o edifício desejado.

Em São Paulo, em 2015, foi desenvolvido o Guia dos Monumentos Nômades, como parte da exposição Memória da Amnésia, com curadoria de Giselle Beiguelman. O guia tinha como objetivo mapear os vários monumentos da cidade, registrando suas diversas localizações ao longo do tempo. O mapeamento foi construído como uma camada do Google MyMaps e depois especializado em realidade aumentada com o uso do Layar (CASIMIRO E MEDEIROS, 2016).
No mesmo artigo, Casimiro e Medeiros mencionam a intervenção Talking Statues em Londres, realizada pela empresa Sing em 2014. Em 2013, o cineasta David Peter Fox lançou o projeto de criar "falas" para as estátuas de Copenhague, que ajudassem a contar suas próprias histórias. Algum tempo depois, o projeto foi estendido a diversas cidades no mundo, com trilhas de áudio ativadas por QR Codes na base das estátuas (http://www.talkingstatues.com/about-1.html).

No Brasil, um grupo de pesquisadores da UNEB desenvolveu o SmartChico (2018) para "indexar aspectos urbanográficos, pontos turísticos e equipamentos culturais públicos dos municípios pertencentes ao chamado Território de Identidade Sertão do Francisco" (ANDRADE E BASTOS, 2017, p. 205). O aplicativo tem a função de auxiliar na divulgação da Cultura do Sertão do São Francisco na internet e criar um objeto de aprendizagem que funcione como ferramenta nas escolas da região (Figura 2).

Em outra vertente, voltada para a visualização de documentos históricos através de mapas, o projeto ImagineRio (EL-DAHDAH E METCALF, 2016) é constituído de um site web responsivo para a visualização dos diferentes mapas e planos da cidade do Rio de Janeiro georreferenciados e sobrepostos a uma base única, associada a uma linha do tempo que permite visualizar a malha urbana, planos urbanos e a base topográfica em seus diferentes momentos históricos. Além disso, o site também traz fotografias históricas localizadas no tempo e no espaço da cidade, sendo um ambiente propício para a construção de comparações espaciais entre diferentes períodos pelos usuários (Figura 2).
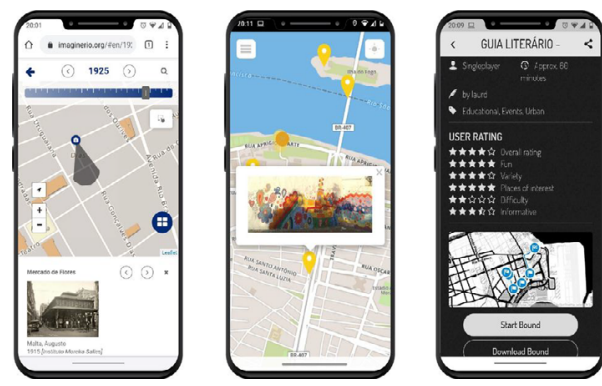

Figura 2: Telas de alguns dos aplicativos estudados, em dispositivos móveis. ImagineRio (à esquerda), SmartChico (ao centro) e ActionBound (à direita).

Os aplicativos estudados corroboram a importância dos meios digitais como facilitadores para a difusão do conhecimento sobre a história da cidade - e para a própria construção da memória coletiva -, principalmente pela capacidade de associar esse conhecimento no espaço. Mais do que uma associação entre um dado histórico e uma coordenada no espaço, quando o usuário percorre os caminhos o conhecimento é inscrito no espaço pelo corpo ali presente, seja em repouso - ativamente buscando os pontos de contato entre o presente e o passado -, seja em movimento - buscando refazer ou descobrir caminhos. 


\section{O GUIA LITERÁRIO}

O guia literário apresentado neste trabalho concentra seu foco na literatura, especificamente contos e crônicas, de modo que o imaginário do leitor seja estimulado pelas imagens evocadas pelos textos, espécie de viagem no tempo alimentada pela capacidade da literatura em evocar imagens urbanas (COUTINHO, FARIA E FARIA 2016, p. 15). O objetivo é que o passeio guiado pela cidade induza o sentimento de identidade e pertencimento, além de fomentar novos questionamentos sobre os processos históricos da cidade, seja pela comparação entre o passado e presente, seja pelo contato com as visões de mundo que ficaram pelo tempo que a literatura (como os projetos) mostra. O objetivo é, enfim, revelar os pontos de contato da cidade física com a cidade imaginada pela literatura, e fazer com que os usuários percebam as histórias bem diversas que permeiam ruas e edifícios, e que ajudaram a cidade a ser como é hoje. O valor de evidenciar esse contraste pode ser entendido a partir da perspectiva de Lange (2009), para o qual as mídias locativas devem ser entendidas como algo com que brincar (no sentido da palavra inglesa "playful"), e boa parte desse sentido reside na exploração das próprias fronteiras entre os domínios digital e real.

A interface do usuário se encontra em andamento, mas a navegação pelo banco de dados será feita, principalmente, pelo mapa (Figura 3). Através dele, o usuário tem acesso aos trechos de literatura ligados a cada ponto da cidade. Os trechos podem ser filtrados por autor, por proximidade, por obra literária (conto, crônica ou livro), por coleções, e, no caso dos livros, por personagens (Figura 4).

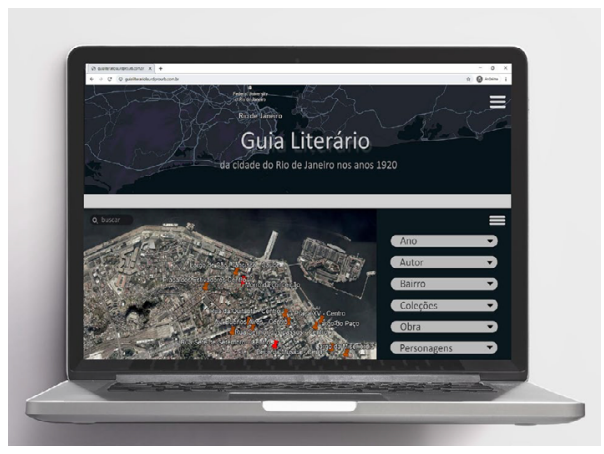

Figura 3: Mockup da página inicial do guia literário, com filtros do mapa. Fonte: LAURD/PROURB/FAU/UFRJ.
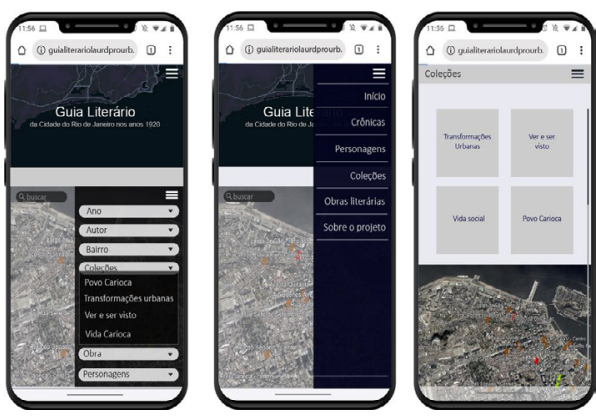

Figura 4: Mockup da página inicial do guia literário, com filtros do mapa. Fonte: LAURD/PROURB/FAU/UFRJ.

As coleções funcionam como categorias, com vocabulário controlado, sendo inseridas pelos pesquisadores, e procuram evidenciar temas gerais de cada trecho. Inicialmente, se baseiam nos modos de vida da população da época e nas mudanças então vivenciadas, como "transformações urbanas" ou "povo carioca" (Figura 5).
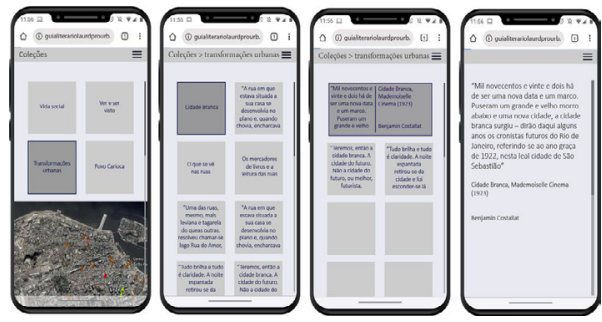

Figura 5: Mockups do site responsivo. Páginas de interação das coleções, simulação de acesso ao trecho literário. Fonte:

\section{LAURD/PROURB/FAU/UFRJ.}

O foco nos contos e crônicas permite, por um lado, uma abordagem menos técnica da cidade, e mais próxima das dinâmicas cotidianas, o que nem sempre fica claro na análise de documentos oficiais ou planos urbanos, por exemplo. Até o fato de não estarem especificamente voltados para a descrição específica das características urbanísticas é entendido, neste contexto, como uma qualidade, ao permitir que os aspectos urbanos apareçam a partir da impressão intrínseca que causam nos escritores, e não como um elemento a ser obrigatoriamente descrito e analisado.

A ideia é de um trabalho que possa ser constantemente atualizado, à medida que novos textos sejam acrescentados ao banco de dados principal. O critério principal é que tenham sido escritos na década de 1920. Embora a estrutura de dados permita décadas diferentes, consideramos que a seleção teria mais potência para retratar um período específico, ajudando a concentrar também os esforços de pesquisa. A partir dos textos completos, começamos a coletar os trechos que se referem a partes específicas da cidade, ou seja, que permitissem uma localização mais precisa em um mapa. Outro critério, de ordem tanto prática quanto conceitual, foi que o recorte espacial seria o centro da cidade. A questão prática está relacionada ao fato de que seria mais fácil testarmos a localização no lugar onde provavelmente teríamos mais pontos. Por outro lado, é no centro do Rio 
de Janeiro que o contraste de um século de diferença se faz sentir de modo mais interessante, justamente por contrapor dinâmicas vibrantes, ainda que cada qual de acordo com sua temporalidade - afinal, o trabalho visa justamente ressaltar a modernidade da cidade na década de 1920.

Mais do que a descrição física dos lugares, o interesse reside na apresentação de como viviam as pessoas, quais as relações e comportamentos que se estabeleciam naqueles espaços e como estes eram efetivamente habitados. A opção pelos trechos se relaciona, por um lado, com o objetivo de ser um guia a ser lido em visita, portanto na rua, o que dificultaria a leitura de textos na integra; por outro, porque torna os trechos menores tornam mais fácil comparar e agregar duas ou mais fontes textuais distintas se referindo ao mesmo local.

Apesar de ser visitável em uma tela de computador, há um esforço considerável para que a posição do usuário seja acrescentada ao mapa e, com isso, possamos induzir à visualização dos trechos literários próximos dos lugares que descrevem, inclusive possibilitando o entrecruzamento de textos anteriormente separados, mas tornados acidentalmente próximos pela referência geográfica.

Os trechos foram coletados em um banco de dados na forma de uma planilha simples, que permitisse maior facilidade de preenchimento nas fases iniciais - e experimentais - do projeto, para posterior migração para uma estrutura mais complexa. A estrutura de dados atual é composta por campos como: título do objeto, título da obra, ano do objeto, ano da obra, autor, citação, pagina, lugar original, lugar atual, bairro, coleções e personagens, além de um campo ID, que permite o relacionamento com 0 arquivo contendo a lista de coordenadas geográficas em KML.

Ainda que inicialmente as coordenadas ficassem na mesma tabela dos demais dados, a necessidade de compatibilizar nossa estrutura com a de padrões seguidos por scripts já existentes acabou levando a essa mudança, evitando que tivéssemos que escrever novas funções para executar comandos semelhantes. Do mesmo modo, a complexidade crescente de categorização dos trechos indica a necessidade de criação de uma estrutura à parte para uma futura implementação de tags.

O guia se constitui em um site web responsivo. Uma das vantagens é que isso não requer a instalação de um aplicativo (nem, de nossa parte, a publicação nas lojas de aplicativos dos dispositivos móveis). Além disso, o site permite concentrar o conhecimento técnico em estruturas e linguagens abertas - e menos específicas (e proprietárias), como aquelas relacionadas aos dispositivos móveis em geral.

O site é baseado em MapBox, HTML 5, CSS e Javascript, enquanto a manipulação dos dados para serem carregados no site é feita através da metodologia ETL Extract, Transform and Load - usando a linguagem Python. Um objetivo secundário do projeto é criar suficiente documentação para outras iniciativas semelhantes baseadas na espacialização de informações (em especial as que incluam a posição do usuário como filtro), proporcionando um instrumento para a apropriação da cidade por meio da arte e das mídias locativas, facilitando a existência de projetos ligados às populações locais, potencialmente contribuindo com vozes mais variadas para o debate sobre a história da cidade e do próprio uso da tecnologia, como colocam Gavin e Mulholland (2008, p. 181); daí a importância de usar ao máximo as linguagens abertas ou ferramentas gratuitas.

Os dados preenchidos na tabela são formatados através de um script em Python para serem vinculados aos dados geográficos importados de um arquivo .KML gerado no Google Earth. Ao final da manipulação, os arquivos são hospedados em um repositório na plataforma GitHub; futuramente, um segundo repositório deve ser empregado exclusivamente para os arquivos HTML. A hospedagem do projeto em repositórios do GitHub serve como estratégia para compartilhamento público do código do trabalho e dos resultados, através da plataforma integrada GitHub Pages, prescindindo de um servidor próprio.

Por meio de mockups do layout e das funcionalidades básicas da interface em programas gráficos e ambientes de testes, pudemos começar a esboçar e avaliar as formas de interação com o banco de dados, incluindo a experiência do usuário em diferentes plataformas, realimentando todo o processo de desenvolvimento do site, além de ajustes na estrutura de dados.

\section{CONCLUSÃO E PERSPECTIVAS}

O desenvolvimento do site responsivo Guia Literário da cidade do Rio de Janeiro nos anos 1920 pretende trazer uma ferramenta a mais de conscientização da importância da memória e do patrimônio da cidade. A partir do reforço da noção das transformações e permanências urbanas, pretende-se com isso ampliar também a noção de responsabilidade sobre o patrimônio urbano não apenas pela salvaguarda dos objetos edificados, mas também pela valorização das dinâmicas das relações e trocas da cidade, o que é especialmente válido para o recorte espacial e temporal. Nem sempre os historiadores da cidade, ao tratar do período, Ihe conferem a importância ou conseguem evocar o dinamismo que emanava dessa cidade em pleno processo de não somente se modernizar, mas de ser moderna.

Trata-se, portanto, de um aplicativo que lida tanto com o patrimônio virtual, criando um ambiente interpretativo com um objetivo de valorização específico, quanto com o turismo literário, recuperando o olhar urbano agudo de autores com grande valor artístico, nem sempre lembrados pelo público em geral. Nessa interseção, portanto, o projeto não apenas traz características de cada um desses campos, mas também as próprias questões de cada um deles.

Os estudos e testes realizados até aqui mostram a importância do método de construção conjunta da estrutura de dados e da interface, que realimentam e reformatam o próprio processo de coleta dos dados, levando a refletir, discutir e aprofundar o conhecimento sobre as questões de organização de dados, das memórias urbanas e da importância dos acessos em diferentes dispositivos. 
Com isso, as próximas etapas incluem, além da ampliação da coleta de dados, aumentando a base de citações, de obras e de autores, a finalização do site responsivo, permitindo os primeiros testes com voluntários de fora do grupo de pesquisa, bem como um aprofundamento na catalogação das citações para um refinamento e ampliação das coleções. Além disso, pretende-se realizar os testes para inclusão de livros na mesma estrutura de dados das crônicas e contos, ampliando as possibilidades de interação, o que inclui também a possibilidade de montagem de roteiros específicos pré-programados. Futuras implementações podem incluir ainda a implementação de funções para permitir a montagem automática de roteiros de visitação a pé a partir de uma seleção de pontos feita pelo usuário.

Por outro lado, tanto quanto o acesso aos dados específicos, a pesquisa pretende disponibilizar os meios para que outros grupos possam deles se apropriar e criar seus próprios guias, com as temáticas que desejarem, multiplicando os olhares sobre a cidade por meio do acesso a distintas camadas narrativas.

\section{AGRADECIMENTOS}

O presente trabalho foi realizado com apoio da Coordenação de Aperfeiçoamento de Pessoal de Níve Superior - Brasil (CAPES) - Código de Financiamento 001 Os autores gostariam de agradecer ainda à FAPERJ, ao CNPq e à UFRJ, pelas bolsas de capacitação técnica, iniciação científica e artística e cultural. Também gostariam de agradecer aos demais membros do LAURD/PROURB/FAU/UFRJ, pelas discussões e contribuições para o trabalho.

\section{REFERÊNCIAS}

Abreu, M. de. (1987). A Evolução Urbana do Rio de Janeiro. Rio de Janeiro: Iplanrio; Zahar.

Actionbound. (2012). Actionbound [Website]. Recuperado de http://actionbound.com/

Andrade, L. A., \& Bastos, C. R. de C. (2017). Recursos criativos, mídia locativa e arte urbana: Experienciando o lugar durante o processo de aprendizagem. Interfaces Científicas Educação, 6(2), 201-212. doi: 10.17564/23163828.2017v6n1p201-212

Bilandzic, M., \& Foth, M. (2012). A review of locative media, mobile and embodied spatial interaction. International Journal of Human - Computer Studies, 70(1), 66-71. doi: 10.1016/j.jjhcs.2011.08.004

Casimiro, G. G., \& Medeiros, M. L. (2016). Cartografias expandidas: Realidade Aumentada e a exposição Memória da Amnésia. Proceedings of the 20th Conference of the Iberoamerican Society of Digital Graphics, 880-884. Recuperado de http://papers.cumincad.org/cgibin/works/paper/sigradi2016 639

Castro, R. (2019). Metrópole à beira-mar: O Rio moderno dos anos 20. São Paulo: Companhia das Letras.

Coutinho, F. N., Faria, D. M. C. P., \& Faria, S. D. (2016). Turismo literário: Uma análise sobre autenticidade, imagem e imaginário. albuquerque: journal of history, 8(16). doi: 10.46401/ajh.2016.v8.2295

Duarte, F. (2002). Crise das matrizes espaciais: Arquitetura, cidades, geopolítica, tecnocultura. São Paulo: Perspectiva / FAPESP.

el-Dahdah, F., \& Metcalf, A. C. (2016). ImagineRio. Recuperado de http://imaginerio.org/
Gaved, M., \& Mulholland, P. (2008). Pioneers, Subcultures and Cooperatives: The Grassroots Augmentation of Urban Places. In A. Aurigi \& F. de Cindio (Orgs.), Augmented Urban Spaces: Artculating the Physical and Electronic City (p. 171-184) Aldershot: Ashgate.

Godin, C., \& Mühlethaler, L. (2005). Édifier: La architecture et le lieu. LaGrasse: Verdier.

Kessel, C. (2001). A vitrine e o espelho: O Rio de Janeiro de Carlos Sampaio. Recuperado de http://www.rio.rj.gov.br/dlstatic/10112/4204430/4101436/a_vit rine_e_o_espelho.pdf

Lange, M. de. (2009). From always-on to always-there: Locative media as playful technologies. In A. de S. e Silva \& D. M. Sutko (Orgs.), Digital Cityscapes: Merging Digital and Urban Playspaces (pp. 55-70). New York: Peter Lang International Academic Publishers

Lemos, A. (2009). Arte e Mídia Locativa no Brasil. Anais do XVIII Encontro da Compós, 1-12. Belo Horizonte: PUC-MG.

MacCannell, D. (1999). The Tourist: A new theory of the leisure class. Berkeley / Los Angeles: University of California.

Manovich, L. (2007). The poetics of augmented space: The art of our time. In F. von Borries, S. P. Walz, \& M. Böttger (Orgs.) Space time play computer games, architecture and urbanism: The next level (pp.251-255). Basel; Boston: Birkhauser.

Medeiros, M. L. (2014). A cidade como interface: Experimentações em realidade aumentada no espaço urbano (Mestrado em Urbanismo, Universidade Federal do Rio de Janeiro, Rio de Janeiro). Recuperado de https://sucupira.capes.gov.br/sucupira/public/consultas/coleta /trabalhoConclusao/viewTrabalhoConclusao.jsf?popup=true\& id trabalho=1958554\#

Mendes, M. C. G. (2007). Na senda estética e poética dos itinerários turísticos e literários: O Vale do Lima (Mestrado em Gestão e Desenvolvimento em Turismo, Universidade de Aveiro, Aveiro). $\quad$ Recuperado de https://ria.ua.pt/handle/10773/4793

Motta, M. S. da. (1994). 1922: Em busca da cabeça do Brasil moderno. Rio de Janeiro: CPDOC. Recuperado de http://bibliotecadigital.fgv.br/dspace/handle/10438/4133

Randonauts, LLC. (2019). Randonautica [Aplicativo móvel]. Recuperado de https://www.randonautica.com/

Salvador, D., \& Baptista, M. M. (2011). O Turismo Cultural como meio de Valorização da Sociedade e das Origens de um Povo: Um roteiro turístico para a cidade de Fortaleza baseado na obra literária Iracema de José de Alencar. Actas do Congresso "A Europa das Nacionalidades - Mitos de Origem: Discursos Modernos e Pós-Modernos", 1-21. Recuperado de https://europe-nations.estudosculturais.com/pdf/0167.pdf

Sant'Anna, T. R. da S. de. (2008). A Exposição Internacional do Centenário da Independência: Modernidade e Política no Rio de Janeiro do início dos anos 1920 (Dissertação de Mestrado em História, Unicamp, São Paulo). Recuperado de http://repositorio.unicamp.br/bitstream/REPOSIP/281848/1/S ant\%27Ana ThaisRezendedaSilvade M.pdf

Santucci, J. (2015). Babélica Urbe: O Rio na crônica dos anos 20. Rio de Janeiro: Rio Books.

Sardo, A. N. (2008). Turismo Literário: Uma forma de valorização do património e da cultura. Egitania Sciencia, 2, 75-96. Recuperado http://www.egitaniasciencia.ipg.pt/artigo.aspx?id=17\&revista= 4

SBTUR. (2019). Nativoo [Aplicativo móvel]. Recuperado de https://page.sbtur.com/nativoo

Souza e Silva, A. de. (2013). Location-aware mobile technologies: Historical, social and spatial approaches. Mobile Media \& Communication, 1(1), 116-121. doi: $10.1177 / 2050157912459492$ 
Syntonize. (2017). Archimaps [Aplicativo móvel]. Recuperado de http://thearchitecturemaps.com/

Talking Statues: About. (2013). Recuperado de http://talkingstatues.com/about-1.html

Tonchidot Corporation. (2009). Sekai Camera [Aplicativo móvel]. Tóquio: Tonchidot Corporation.
Tuan, Y.-F. (2007). Space and place: The perspective of experience. Minneapolis: University of Minnesotta Press.

Zeffiro, A. (2012). A location of one's own: A genealogy of locative media. Convergence: The International Journal of Research into New Media Technologies, 18(3), 249-266. doi: $10.1177 / 1354856512441148$ 